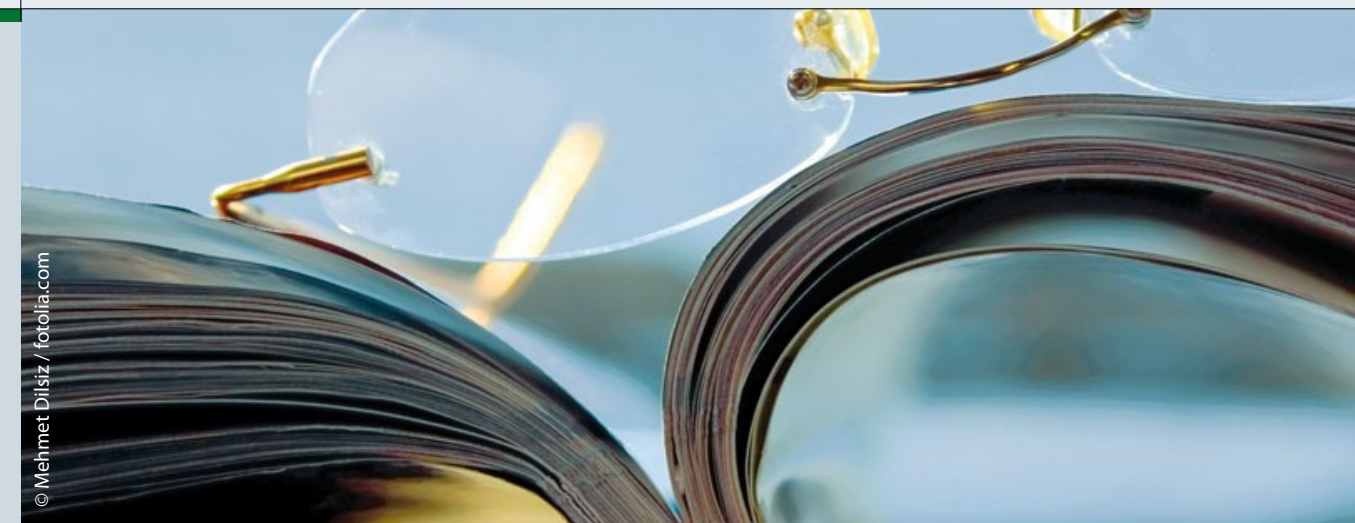

\section{LUTS: Sägepalmenextrakt auch hochdosiert ein Placebo}

Die Dosis macht nicht die Wirkung: Selbst in der dreifachen Standarddosierung richtet Sägepalmenextrakt gegen die Symptome des unteren Harntrakts bei benigner Prostatahyperplasie nicht mehr aus als ein Placebo.

Extrakte aus Früchten der Sägepalme - (Serenoa repens) finden bei Symptomen des unteren Harntrakts (LUTS) nach wie vor breite Anwendung - obwohl in neueren Studien kein Nutzen nachgewiesen werden konnte. Auf eine ungenügende Dosierung sind die gescheiterten Wirksamkeitsnachweise wohl nicht zurückzuführen. Eine Erhöhung der Tagesdosis von den üblichen $320 \mathrm{mg}$ auf 960 $\mathrm{mg}$ ist genauso wenig Erfolg versprechend.
An der placebokontrollierten randomisierten Doppelblindstudie beteiligten sich 369 Männer mit LUTS im Zusammenhang mit einer benignen Prostatahyperplasie $(\mathrm{BPH})$. Die Patienten hatten einen maximalen Harnfluss von $4 \mathrm{ml} / \mathrm{s}$, der Schweregrad ihrer Symptome wurde mit dem American Urological Assocation Symptom Index (AUASI)-Score zwischen 8 und 24 Punkten eingestuft. Behandelt wurde 72 Wochen lang mit Placebo oder einem standardisierten Ex-

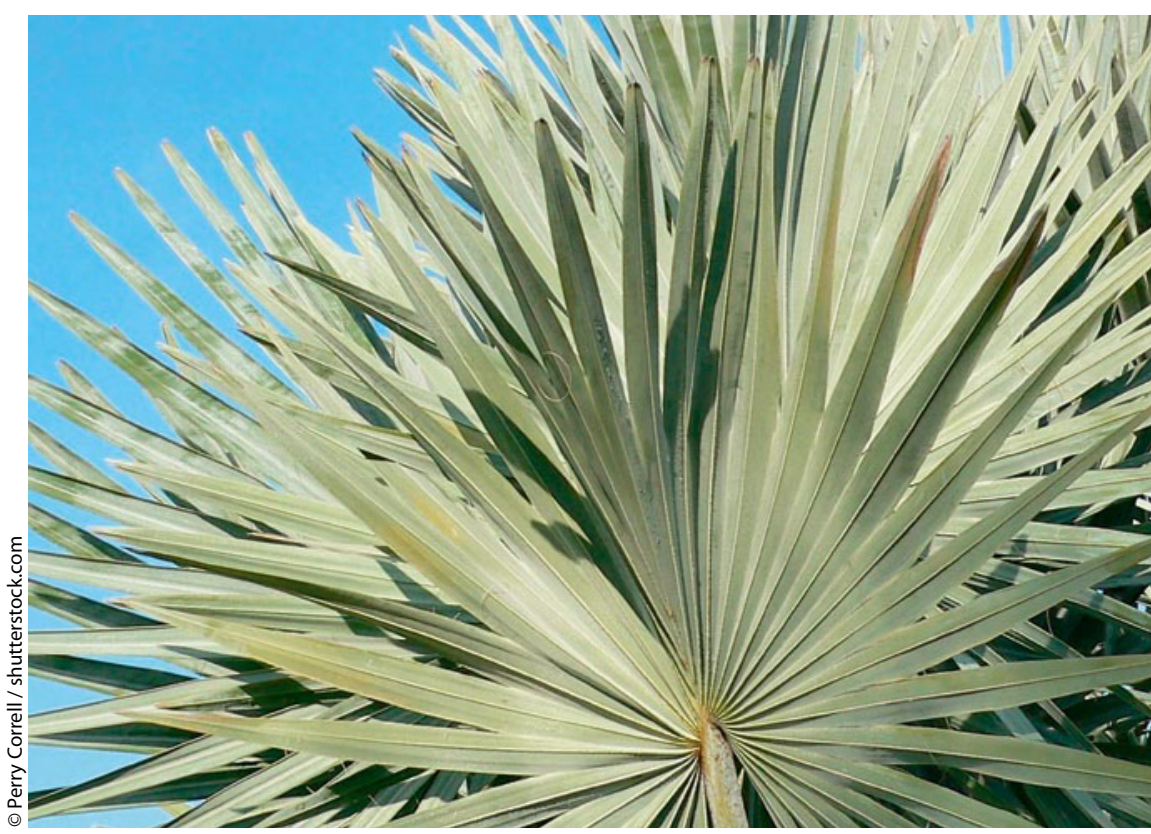

Sägepalme (Serenoa repens): bei BPH-Symptomen besser nicht auf deren Extrakt verlassen

trakt aus Sägepalmenfrüchten (Gelkapseln mit 320 mg Wirkstoff). Die Behandlung wurde mit täglich einer Kapsel begonnen, ab Woche 24 wurde die Dosis auf zwei, ab Woche 48 auf drei Kapseln erhöht.

Nach 72 Wochen war der AUASI-Score unter dem Phytotherapeutikum von 14,42 auf 12,22 Punkte gesunken. Unter Placebo fiel die Besserung etwas deutlicher aus, mit einem Rückgang von 14,69 auf 11,70 Punkte (Differenz 0,79 Punkte). Eine Abnahme des AUASI-Score von mindestens drei Punkten erreichten $42,6 \%$ beziehungsweise $44,2 \%$ der Patienten. Bei den sekundären Endpunkten (z.B. Nykturie, Spitzenharnfluss, Restharnvolumen, PSA-Wert, Gesamturteil des Patienten, Sexualfunktion, Kontinenz) kam der Sägepalmenextrakt ebenfalls nicht über Placeboeffekte hinaus. Der einzige positive Befund: Auch in Bezug auf die Nebenwirkungen war kein Unterschied zwischen Sägepalmenextrakt und Placebo feststellbar.

Fazit: Diese Ergebnisse könnten das endgültige Aus für die Sägepalme in der Urologie bedeuten. Die Autoren vermuten, dass sich die Negativresultate auch auf andere als den verwendeten (ethanolischen) Sägepalmenextrakt übertragen lassen. Nach ihren Worten gebe es inzwischen eine Serie von Negativstudien mit verschiedenen Sägepalmenpräparaten. Das mache es zunehmend unwahrscheinlich, dass eine Dosierung irgend eines anderen Präparats sich als besser als Placebo erweisen werde.

Dr. Beate Schumacher

Barry MJ et al. Effect of Increasing Doses of Saw Palmetto Extract on Lower Urinary Tract Symptoms. JAMA 2011; 306: 1344-51 